\title{
Influence of Amino Acid Composition and Phosphorylation on the Ion Yields of Peptides in MALDI-MS
}

\author{
Daiki Asakawa, Shohey Moriguchi, Mitsuo Takayama
}

Graduate School of Nanobioscience, Yokohama City University, 22-2 Seto, Kanazawa-ku, Yokohama, 236-0027, Japan

\begin{abstract}
The influence of arginine (Arg), lysine (Lys), and phenylalanine (Phe) residues and phosphorylation on the molecular ion yields of model peptides have been quantitatively studied using matrix-assisted laser desorption/ionization (MALDI) mass spectrometry in both positive- and negative-ion mode. The results obtained from these experiments have been interpreted from the standpoint of two different components, namely, desorption and ionization, on the basis of the physicochemical properties of constituent amino acids of the model peptides. The presence of basic residues such as Arg and Lys enhanced the ion yields of protonated molecules $[\mathrm{M}+\mathrm{H}]^{+}$. An $\mathrm{N}$-terminal rather than a C-terminal Arg residue was advantageous for the formation of both $[\mathrm{M}+\mathrm{H}]^{+}$and $[\mathrm{M}-\mathrm{H}]^{-}$. The presence of the Phe residue resulted in the increase of the ion yields of both $[\mathrm{M}+\mathrm{H}]^{+}$and $[\mathrm{M}-\mathrm{H}]^{-}$. In contrast, the presence of phosphate group(s) contributed to the suppression of the yields of both $[\mathrm{M}+\mathrm{H}]^{+}$and $[\mathrm{M}-\mathrm{H}]^{-}$due to the loss of phosphate group. The detection limits for both $[\mathrm{M}+\mathrm{H}]^{+}$and $[\mathrm{M}-\mathrm{H}]^{-}$of model peptides have been evaluated.
\end{abstract}

Key words: Ion yield, MALDI, Rate of desorption, Ionization efficiency, Amino acid composition

\section{Introduction}

$\mathrm{M}$ ass spectrometry has been used as a powerful analytical tool in a wide variety of scientific fields because of its high sensitivity and ability to elucidate chemical structures. Soft ionization methods such as matrix-assisted laser desorption/ionization (MALDI) [1-3] and electrospray ionization (ESI) $[4,5]$ are recognized as an indispensable analytical tool for biological polymers. In particular, peptide-mass fingerprinting (PMF) has become a common approach for the characterization of proteins $[6,7]$. In PMF the parental protein is cleaved into smaller peptides with enzymes and the resulting digests are analyzed by ESIMS or MALDI-MS.

In MALDI analysis, a mixture of the analyte and the matrix is irradiated by a UV-laser, and gas-phase protonated and deprotonated analytes are generated through desorption or ablation. However, a significant number of neutral molecules

Correspondence to: Mitsuo Takayama; e-mail: takayama@yokohama-cu.ac.jp are produced as a result of laser desorption events, so that the ion-to-neutral ratio of the MALDI process has been estimated to be less than $10^{-5}$ [8]. To exploit these desorbed neutral molecules, Cotter performed laser desorption using a chemical ionization source where the desorbed neutral molecules were ionized with reagent ions generated from a chemical ionization gas [9]. In the following years, several different approaches were used to ionize the neutral molecules produced after laser desorption events. These methods include chemical ionization [9-11], electron ionization [12], laser ionization [13-15], and electrospray ionization [16]. The decoupling of desorption and ionization processes allows for the individual optimization of the two steps with increased gas-phase ion formation efficiency. For example, the atmospheric pressure laser desorption/ chemical ionization (AP-LD/CI) technique, which combines $10.6 \mu \mathrm{m}$ infrared laser desorption and chemical ionization with corona discharge provides an approximately 150-fold increase in analyte ions compared with the ion abundance generated by atmospheric pressure infrared MALDI [11].

The reports described above suggest that all ionization processes at least MALDI in mass spectrometry are divided 
into two different components, namely, vaporization (desorption) and ionization. These two processes are quite different, with vaporization being a physical process that forms gaseous species from the condensed-phase analyte, while ionization is a thermochemical process that forms analyte ionic species such as $\mathrm{M}^{+},[\mathrm{M}+\mathrm{H}]^{+}$, and $[\mathrm{M}-\mathrm{H}]^{-}$. In order to understand the ion yields in soft ionization methods, here we use a constitutional form where we have divided the total ionization processes $J_{i}$ into ionization efficiency of analyte molecules $I$ and the rate of desorption or vaporization of analyte molecules $J_{v}$ as follows [17]:

$$
J_{i}=I J_{v}
$$

The ionization efficiency $I$ [ions/molecules] can be related to thermochemical quantities such as proton affinity, gas-phase basicity, ionization energy, or electron affinity of a given analyte. The quantity $J_{v}$ [molecules $\left./ \mathrm{cm}^{2} \mathrm{~s}\right]$ represents the ability of analyte molecules to desorb or vaporize from the condensed- to gas-phase.

The molecular ion yields of peptides in soft ionization methods are strongly dependent on their intrinsic physicochemical properties, which originate from the individual nature of the side chains of the constituent amino acids. Amino acids have several different physicochemical properties such as acidity, basicity, and hydrophobicity, which are associated with the characteristics of the amino acid side chain. It has been previously reported that the ion yields of protonated and deprotonated peptides are affected by the physicochemical properties of individual amino acids in soft ionization methods such as MALDI, ESI and fast atom bombardment (FAB) [17, 18]. In FAB, the ion yields of peptides depend on proton affinity, gas-phase acidity and hydrophobicity [17, 18]. Proton affinity and gas-phase acidity are important chemical factors in the formation of $[\mathrm{M}+\mathrm{H}]^{+}$and $[\mathrm{M}-\mathrm{H}]^{-}$, respectively, and these factors can be rationalized by ionization efficiency $I$ in Equation 1. In contrast, the ion yields of both $[\mathrm{M}+\mathrm{H}]^{+}$and $[\mathrm{M}-\mathrm{H}]^{-}$are enhanced by the presence of hydrophobic amino acid residues such as Leu and Ile. The hydrophobic nature of an analyte is an advantageous factor for desorption from the liquid surface by means of the rate of desorption of analyte molecules, $J_{v}$ in Equation 1 . In the case of ESI, the total ion yields of peptides are also dependent on hydrophobicity for both positive and negative ions [17]. Two mechanisms, ion evaporation model [19] and equilibrium partitioning model [20], have been proposed to account for the formation of gas-phase ions in ESI. In the both models, the hydrophobic nature of an analyte is an advantageous factor for the evaporation and ionization in the ESI process. The ion yield of peptides in MALDI was mainly dependent on proton affinity and gas-phase acidity by means of the ionization efficiency $I$ in Equation $1[17,18]$. However, no significant correlations were found between ion yields and hydrophobicity in MALDI. The reason for the lack of dependence of ion yields on hydrophobicity is presumably related to the fact that the analyte molecules are not dissolved into liquid matrix, but are incorporated into a solid matrix. Instead, the presence of aromatic amino acid residues such as Phe and Tyr contributes to the increase in the ion yields possibly via interactions with the matrix molecules that are also generally aromatic $[17,18,21,22]$. The phosphorylation of peptides decreases the ion yield of $[\mathrm{M}+\mathrm{H}]^{+}$and gives a relatively large ion yield of $[\mathrm{M}-\mathrm{H}]^{-}[23]$.

In the work described here, the effects of Arg, Lys, and Phe residues and phosphorylation on the ion yields of peptides is quantitatively evaluated in positive and negative ion MALDI-MS. The model peptides such as threonine (T)cluster and ACTH-based series were designed specifically for the evaluation of ion yields.

\section{Experimental}

\section{Materials}

All peptides were purchased from Peptide Institute (Osaka, Japan). The sequences of peptides are summarized in Table 1. The MALDI matrix $\alpha$-cyano-4-hydroxycinnamic acid (CHCA) was purchased from Sigma-Aldrich (Steinheim, Germany). Trifluoroacetic acid and acetonitrile were purchased from Wako Pure Chemicals (Osaka, Japan). All reagents were used without further purification, except for water, which was purified through a MilliQ water purification system (Millipore, Billerica, MA, USA). A Teflon sheet used as a water-repellent coat was purchased from Sumitomo-3 M (Tokyo, Japan).

\section{Sample Preparation}

Analyte peptides were dissolved in water. Each peptide sample $(5 \mu \mathrm{L})$ was mixed with $5 \mu \mathrm{L}$ of saturated solution of CHCA in water/acetonitrile (1:1, vol/vol) with $0.1 \%$ TFA. A volume of $1 \mu \mathrm{L}$ of sample solution was deposited onto a stainless steel plate or Teflon seat on the stainless plate. The solvents were removed by allowing evaporation in air at

Table 1. Monoisotopic Mass $\left(\mathrm{M}_{\mathrm{m}}\right)$ and Sequence of T-cluster Peptides and ACTH-based Peptides

\begin{tabular}{|c|c|c|}
\hline Peptide & $\mathrm{M}_{\mathrm{m}}$ & Sequence \\
\hline $\mathrm{T} 7$ & 725.35 & T T T T T T T \\
\hline RT6 & 780.41 & R T T T T T T \\
\hline T6R & 780.41 & T T T T T T R \\
\hline RT5F & 826.43 & R T T T T T F \\
\hline FT5R & 826.43 & F T T T T T R \\
\hline KT6 & 752.40 & К T T T T T T \\
\hline ACTH18-35 (A1) & 1977.95 & RPVKVYPNGAEDESAEAF \\
\hline$\left[\mathrm{pTyr}^{23}\right]-\mathrm{ACTH} 18-35$ (A1p1) & 2057.93 & RPVKVpYPNGAEDESAEAF \\
\hline$\left[\mathrm{pTyr}^{23}, \mathrm{pSer}^{31}\right]$-ACTH18-35 (A1p2) & 2137.91 & RPVKVpYPNGAEDEpSAEAF \\
\hline$\left[\mathrm{Arg}^{36}\right]-\mathrm{ACTH} 19-36$ (A2) & 1977.95 & PVKVYPNGAEDESAEAFR \\
\hline$\left[\mathrm{Arg}^{36}\right]-\mathrm{ACTH} 18-36$ (A3) & 2134.05 & RPVKVYPNGAEDESAEAFR \\
\hline ACTH19-36 (A4) & 1918.90 & PVKVYPNGAEDESAEAFP \\
\hline ACTH22-39 (A5) & 1983.88 & VYPNGAEDESAEAFPLEF \\
\hline$\left[\mathrm{Arg}^{22}\right]-\mathrm{ACTH} 22-39$ (A6) & 2040.91 & RYPNGAEDESAEAFPLEF \\
\hline
\end{tabular}


room temperature. Images of the dried samples were acquired on an optical microscope, BX51 (Olympus, Tokyo, Japan). The sizes of the mixed crystals of sample and CHCA loaded on the stainless plate and Teflon covered stainless plate were estimated to be $2.79 \pm 0.35 \times 10^{-6} \mathrm{~m}^{2}$ and $1.83 \pm$ $0.30 \times 10^{-6} \mathrm{~m}^{2}$, respectively.

\section{Matrix-Assisted Laser Desorption/Ionization Mass Spectrometry}

MALDI mass spectra were obtained using a time-of-flight mass spectrometer, AXIMA-CFR (Shimadzu, Kyoto, Japan) equipped with a nitrogen laser (337 nm wavelength) operating at a pulse rate of $10 \mathrm{~Hz}$. The pulse width of the laser was $4 \mathrm{~ns}$. The laser spot size on the target substrate was about $100 \mu \mathrm{m}$ in diameter. The ions generated by MALDI were accelerated using $20 \mathrm{kV}$ with delayed extraction. The analyzer was operated in reflectron mode and the ions were detected using a microchannel plate detector. A total of 500 shots were accumulated for each mass spectrum acquisition. The laser irradiation point was automatically changed every 5 laser shots using the raster function installed on the AXIMA-CFR instrument. The ion yields and limit of detection of peptides were evaluated by averaging 10 times measurement.

\section{Results and Discussion}

\section{Ion Yield of Threonine (T)-Cluster Peptides}

In this study, CHCA was used as a matrix because CHCA gives ion signals without sweet spots when compared with other matrices such as 2,5-dihydroxybenzoic acid, and allows tolerance of quantitative results. Here we chose Tclusters which are chemically neutral in nature, as model peptides (Table 1). The ion yields of protonated and deprotonated molecules from $10 \mathrm{pmol}$ of T-cluster peptides were obtained in the signal-to-noise ratio $(\mathrm{S} / \mathrm{N})$, as shown in Figure 1 . In the positive ion mode, the analyte peptides RT5F (S/N 933), FT5R (S/N 699), RT6 (S/N 432) and T6R ( $\mathrm{S} / \mathrm{N} 314$ ) gave relatively high ion yields, while the peptides KT6 (S/N 157) and T7 (S/N 27.5) gave medium and low ion yields, respectively. In the negative ion mode, RT5F (S/N 65.1), RT6 (S/N 52.8), T7 (S/N 49.5) and FT5R (S/N 46.0) gave relatively high ion yields, while T6R (S/N 15.3) and KT6 (S/N 6.8) gave low ion yields.

An enhancement effect of an Arg residue on the ion yield of $[\mathrm{M}+\mathrm{H}]^{+}$was observed by comparing arginine containing peptides RT6 (S/N 432) and T6R (S/N 314) with the Arg free peptide T7 (S/N 27.5). Such an enhancement effect of the Arg residue on ion yields of $[\mathrm{M}+\mathrm{H}]^{+}$can be attributed to its basic nature. The presence of the Arg residue facilitates the protonation reaction and thus enhances the ion yields of $[\mathrm{M}+\mathrm{H}]^{+}$, as described in our previous report [18]. The positive influence of the Arg residue on the ion yields of [M $+\mathrm{H}^{+}$is interpreted via the term corresponding to the

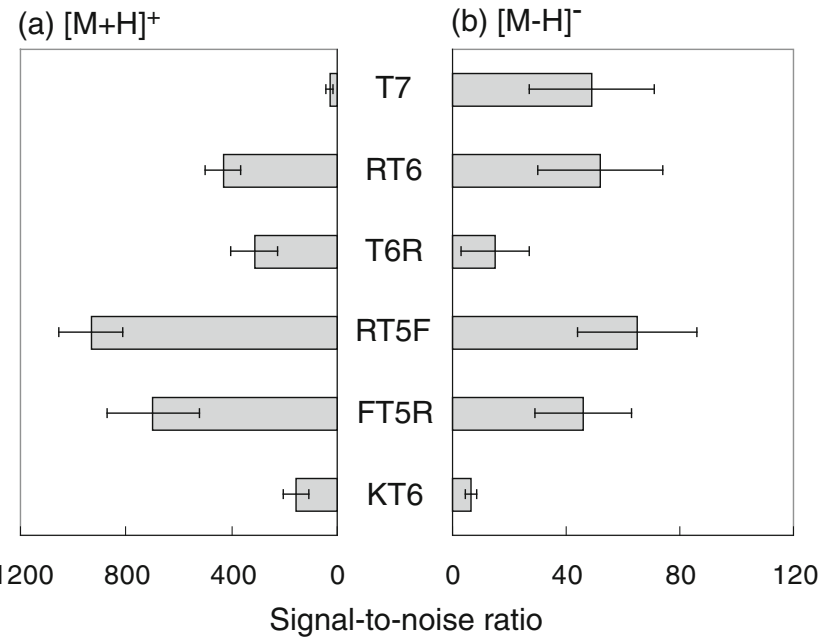

Figure 1. Yields of molecular-related ions from $10 \mathrm{pmol}$ Tcluster peptides in MALDI. (a) Positive ion yields of $[\mathrm{M}+\mathrm{H}]^{+}$ and (b) negative ion yields of $[\mathrm{M}-\mathrm{H}]^{-}$

ionization efficiency $I$ in Equation 1. In contrast, it is expected that the deprotonation reaction which gives [M$\mathrm{H}]^{-}$would be suppressed by the presence of an Arg residue. However, the conversion of Thr into Arg at the N-terminus had almost no affect on the ion yields of $[\mathrm{M}-\mathrm{H}]^{-}$, as shown in Figure 1. The presence of the Arg residue enhances the ion yields of $[\mathrm{M}-\mathrm{H}]^{-}$, as described in our previous report [17]. It is unlikely that the basic Arg residue is effectively deprotonated. Therefore, the presence of an Arg residue may be advantageous for desorption from the crystalline matrix into the gas-phase in the MALDI process. In contrast to RT6, alteration of Thr to Arg at the C-terminus significantly reduced the ion yield of $[\mathrm{M}-\mathrm{H}]^{-}$(Figure 1). Negative ion MALDI mass spectra of RT6 and T6R are shown in Figure 2. It should be noted however, that the presence of an Arg residue at the $\mathrm{C}$-terminus significantly reduces the ion yield of $[\mathrm{M}-\mathrm{H}]^{-}$. In positive ion mode, RT6 also gave a higher ion yield of $[\mathrm{M}+\mathrm{H}]^{+}$than T6R. The results indicate that the presence of the Arg residue at the C-terminus would be disadvantageous for the formation of both $[\mathrm{M}+\mathrm{H}]^{+}$and $[\mathrm{M}-\mathrm{H}]^{-}$. It is likely that the C-terminal carboxyl group interacts with the Arg side chain to form a Zwitterion in the gas-phase, as previously reported [24].

The conversion of a Thr residue to a Phe residue (RT6 into RT5F and T6R into FT5R) resulted in an enhancement of the ion yield of both $[\mathrm{M}+\mathrm{H}]^{+}$and $[\mathrm{M}-\mathrm{H}]^{-}$. It is likely that the aromatic group of the Phe residue is advantageous for the process of desorption from crystalline matrix to gasphase and thus results in the increase of the ion yields of both $[\mathrm{M}+\mathrm{H}]^{+}$and $[\mathrm{M}-\mathrm{H}]^{-}$. The enhancement effect of aromatic amino acids on the ion yields in MALDI is consistent with previous reports [17, 18, 21, 22]. It is interpreted via the term corresponding to the rate of desorption of analyte molecules, $J_{v}$ in Equation 1.

Comparison of the ion yields for T7 and KT6 in Figure 1, illustrates that the conversion of Thr into Lys at the N- 
$(48 \mathrm{mV})$
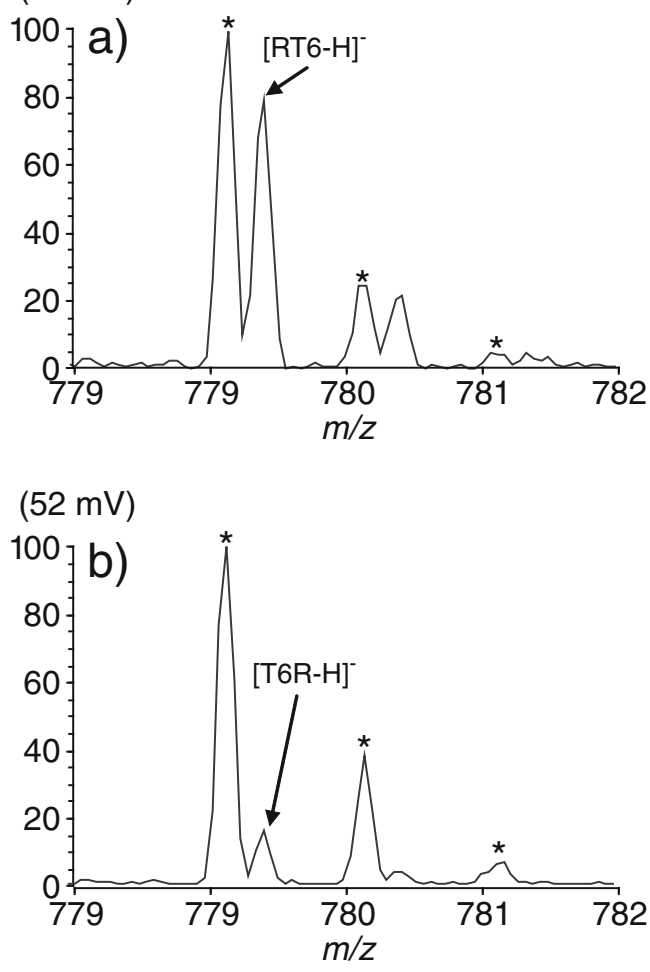

Figure 2. Negative ion MALDI mass spectra, (a) 10 pmol of RT6, and (b) 10 pmol of T6R. Asterisk indicates background peaks originating from matrix

terminus increases the ion yield of $[\mathrm{M}+\mathrm{H}]^{+}$from $\mathrm{S} / \mathrm{N} 27.5$ to $\mathrm{S} / \mathrm{N} 157$, while causing a decreased ion yield of $[\mathrm{M}-\mathrm{H}]^{-}$from $\mathrm{S} / \mathrm{N} 49.5$ to $\mathrm{S} / \mathrm{N} 6.8$. This suggests that the presence of a highly basic Lys residue increases the formation of $[\mathrm{M}+\mathrm{H}]^{+}$, so that a smaller fraction of peptides could form the $[\mathrm{M}-\mathrm{H}]^{-}$. Thus, the presence of the Lys residue would be advantageous for the formation of $[\mathrm{M}+\mathrm{H}]^{+}$, but disadvantageous for the formation of $[\mathrm{M}-\mathrm{H}]^{-}$by means of the ionization efficiency $I$ in Equation 1.

\section{Ion Yield of ACTH-Based Peptides}

We have chosen ACTH-based peptides as model peptides, because ACTH and related peptides have been often used for evaluating the MS machine performances such as resolution and as a calibrant chemical. The ion yields of protonated and deprotonated molecules from 100 fmol of ACTH-based peptides (Table 1) were obtained in the signal-to-noise ratio $(\mathrm{S} / \mathrm{N})$, as shown in Figure 3. In positive ion mode, the analyte peptides A1 (S/N 390) and A6 (S/N 195) gave relatively high ion yields, while the peptides $\mathrm{A} 2(\mathrm{~S} / \mathrm{N} 130), \mathrm{A} 1 \mathrm{p} 1$ (S/N 108), and $\mathrm{A} 3$ ( $\mathrm{S} / \mathrm{N}$ 58.4) gave medium ion yields. The peptides $\mathrm{A} 4$ (S/N 13.4), A1p2 (S/N 8.1), and A5 (S/N 2.1) gave low ion yields. In negative ion mode, $\mathrm{A} 1$ (S/N 49), A1p1 (S/N 34), A5 (S/N 30), A6 (S/N 23), and A4 (S/N 16) gave relatively (a) $[\mathrm{M}+\mathrm{H}]^{+}$

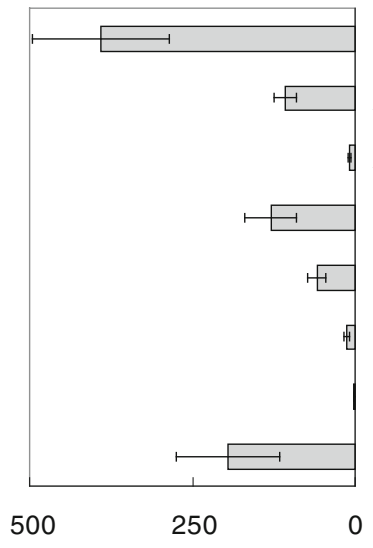

(b) $[\mathrm{M}-\mathrm{H}]^{-}$

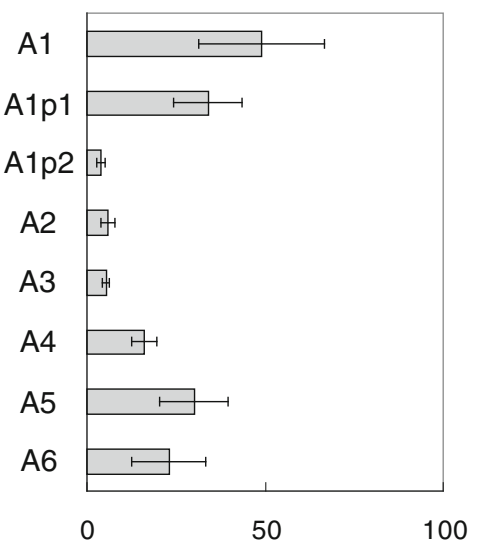

Figure 3. Yields of molecular-related ions from $100 \mathrm{fmol}$ ACTH-based peptides. (a) Yields of $[\mathrm{M}+\mathrm{H}]^{+}$in positive ion MALDI and (b) yields of $[\mathrm{M}-\mathrm{H}]^{-}$in negative ion MALDI

high ion yields, while $\mathrm{A} 2$ (S/N 5.9), A3 (S/N 5.3), and A1p2 (S/N 4.0) gave low ion yields.

A definitive enhancement effect of an Arg residue on the ion yield of $[\mathrm{M}+\mathrm{H}]^{+}$was observed by comparing arginine containing peptides A1 (S/N 390) and A2 (S/N 130) with the Arg free peptide A4 (S/N 13.4). The same signal increase in the presence of the Arg residue is observed when comparing A5 (S/N 2.1) and A6 (S/N 195). The only difference between $\mathrm{A} 5$ and $\mathrm{A} 6$ is the alteration of $\mathrm{Val}$ at the $\mathrm{N}$ terminus into Arg. The presence of an Arg residue facilitates the protonation reaction and thus enhances the ion yield of $[\mathrm{M}+\mathrm{H}]^{+}$. Comparison of the arginine containing peptides A1 and $\mathrm{A} 2$ demonstrates that $\mathrm{A} 1$ gives a higher ion yield of $[\mathrm{M}+$ $\mathrm{H}]^{+}$than $\mathrm{A} 2$. The difference between $\mathrm{A} 1$ and $\mathrm{A} 2$ is the moving of the Arg residue from the $\mathrm{N}$ - to the $\mathrm{C}$-terminus in $\mathrm{A} 1$. The presence of the $\mathrm{N}$-terminal Arg residue was advantageous for the formation of $[\mathrm{M}+\mathrm{H}]^{+}$rather than that of the C-terminal Arg residue. The result is in agreement with the case of T-cluster peptides, as shown in Figure 1. In contrast, both A1 and A2 gave a higher ion yield of $[\mathrm{M}+\mathrm{H}]^{+}$than $\mathrm{A} 3$, even though $\mathrm{A} 3$ has Arg residues at both the $\mathrm{N}$ - and $\mathrm{C}$-terminus. The presence of two Arg residues instead of one seems to be a disadvantage for the ion yield of $[\mathrm{M}+\mathrm{H}]^{+}$.

In negative ion mode, $\mathrm{A} 2(\mathrm{~S} / \mathrm{N} 5.9)$ and $\mathrm{A} 3(\mathrm{~S} / \mathrm{N}$ 5.3) gave lower ion yields of $[\mathrm{M}-\mathrm{H}]^{-}$than the other ACTHbased peptides A1, A4, A5, and A6. A1 gave higher ion yield of $[\mathrm{M}-\mathrm{H}]^{-}$than A4. The difference between the A1 and A4 is the addition of an Arg residue to the N-terminus and removal of a Pro residue from the C-terminus of A4. This result suggests that the presence of the Arg residue at the N-terminus contributes to enhancement of the yields of $[\mathrm{M}-\mathrm{H}]^{-}$. However, it is unlikely that the basic Arg residue is effectively deprotonated. The presence of the Arg residue at the N-terminus may be advantageous for the desorption from crystalline matrix to gas-phase in MALDI. In contrast to $\mathrm{A} 1, \mathrm{~A} 2$ gave a lower ion yield of $[\mathrm{M}-\mathrm{H}]^{-}$than $\mathrm{A} 4$. Comparison of the sequence of A2 and A4 suggests that it is 
the conversion of Pro into Arg at the C-terminus, which reduces the ion yields of $[\mathrm{M}-\mathrm{H}]^{-}$. The results indicate that the presence of the Arg residue at the $\mathrm{N}$-terminus increases the ion yield of $[\mathrm{M}-\mathrm{H}]^{-}$, while the presence of the Arg residue at the $\mathrm{C}$-terminus significantly reduces the ion yield of $[\mathrm{M}-\mathrm{H}]^{-}$.

Comparison of A4 and A5, demonstrates that the difference in sequence between these peptides is the removal of the Pro-Val-Lys component from the N-terminus and addition of $\mathrm{Leu}-\mathrm{Glu}-\mathrm{Phe}$ to the $\mathrm{C}$-terminus of A5. A4 gave a higher ion yield of $[\mathrm{M}+\mathrm{H}]^{+}$than $\mathrm{A} 5$, while the ion yield of $[\mathrm{M}-\mathrm{H}]^{-}$in $\mathrm{A} 4$ is lower than that of A5. The presence of the highly basic Lys residue and the removal of the highly acidic Glu residue in A4 would be advantageous for the formation of $[\mathrm{M}+\mathrm{H}]^{+}$, but disadvantageous for the formation of $[\mathrm{M}-$ $\mathrm{H}]^{-}$by means of the ionization efficiency $I$ in Equation 1 .

\section{Influence of Phosphorylation on the Ion Yield of ACTH-Based Peptides}

To evaluate the ion yields of phosphorylated peptides in MALDI-MS, the ion yields of non-phosphorylated peptide A1, mono-phosphorylated peptide A1p1, and di-phosphorylated peptide A1p2 were compared. The positive and negative ion yields of these peptides are summarized in Figure 3. A suppression effect of phosphorylation on the ion yields of $[\mathrm{M}+\mathrm{H}]^{+}$was observed in the comparison of nonphosphorylated peptide A1 (S/N 390) with phosphorylated peptides A1p1 (S/N 108) and A1p2 (S/N 8.1). It is likely that the negative contribution of phosphorylation on the ion yields of $[\mathrm{M}+\mathrm{H}]^{+}$is due to the acidic nature of the phosphate group. In contrast to the ion yields of $[\mathrm{M}+\mathrm{H}]^{+}$, it would be expected that the presence of a phosphate group would enhance the ion yields of $[\mathrm{M}-\mathrm{H}]^{-}$. However, the opposite results were obtained. The phosphorylation of the

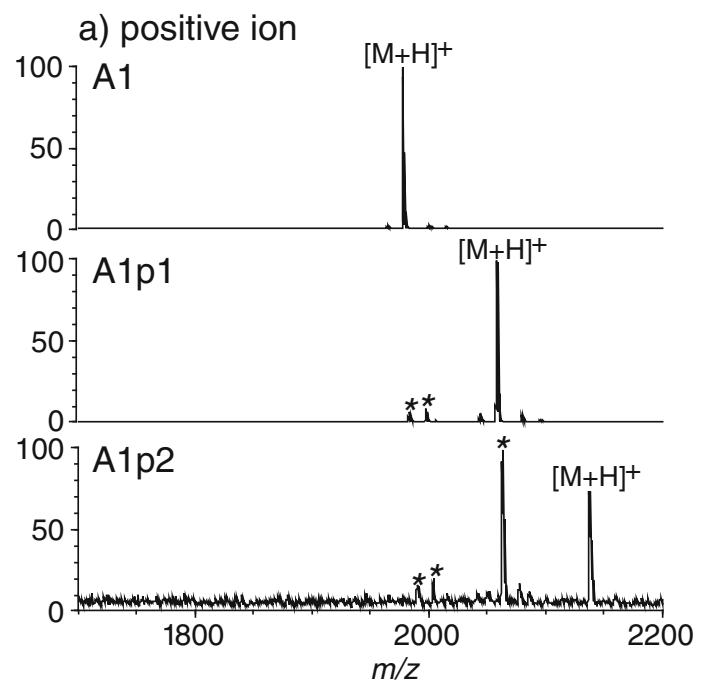

Tyr residue in A1 to give A1p1 decreased the ion yield from $\mathrm{S} / \mathrm{N} 49$ to 34. A similar signal decrease upon the addition of a further phosphate group is observed in the comparison of A1p1 (S/N 34) and A1p2 (S/N 4.0). The results indicate that the presence of phosphate group(s) contributes to suppression of the ion yields of both $[\mathrm{M}+\mathrm{H}]^{+}$and $[\mathrm{M}-\mathrm{H}]^{-}$. The positive- and negative-ion MALDI mass spectra of these peptides are shown in Figure 4. Metastable ion peaks were observed in the mass spectra of phosphorylated peptides A1p1 and A1p2, while these peaks are almost absent from the mass spectra of non-phosphorylated peptide A1. It is known that the loss of phosphoric acid is the most abundant fragmentation process for phosphorylated peptides [23]. This suggests that the presence of a phosphate group is disadvantageous for the detection of ion signals of phosphorylated peptides due to the loss of the phosphate group (s). However, it should be noted that both the positive and negative ion yields of $\mathrm{A} 1 \mathrm{p} 2$ are significantly lower than those of A1 and A1p1 (Figure 3), and the relative abundance of metastable ion peaks of $\mathrm{A} 1 \mathrm{p} 2$ is higher than that of $\mathrm{A} 1 \mathrm{p} 1$ (Figure 4). It has previously been reported that a phosphate group at Tyr is stable compared with that at Ser and Thr residues because of the lack of $\beta$-elimination pathways [2527]. It is likely that the negative contribution of phosphorylation at the Ser residue on the ion yield is due to lower stability of the phosphate group.

\section{Detection Limit of Model Peptides}

Dilution tests were performed to evaluate the detection limit of model peptides in MALDI. The detection limits of protonated and deprotonated molecules are summarized in Table 2. A similar trend was obtained for the ion yields of model peptides as shown in Figures 1 and 3. Comparison of the ACTH-based peptides with the T-cluster peptides

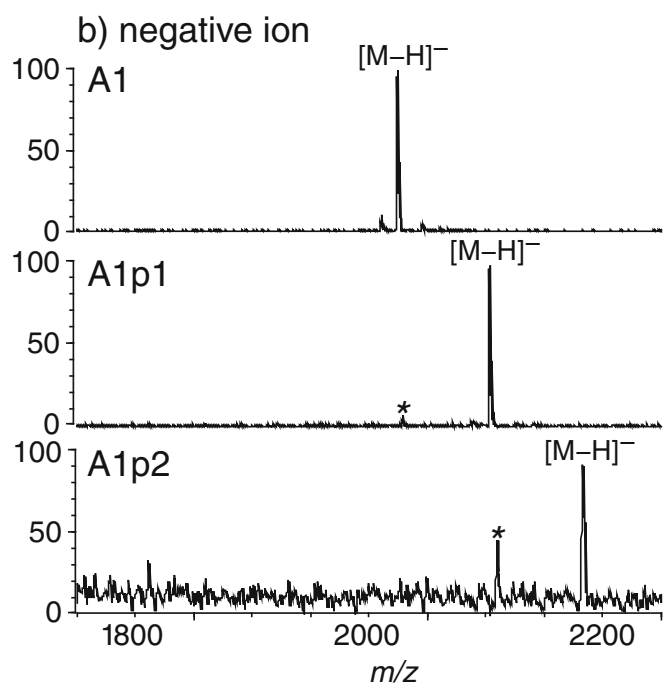

Figure 4. (a) Positive- and (b) negative-ion MALDI mass spectra of $100 \mathrm{fmol}$ of A1, A1p1, and A1p2. Asterisk indicates metastable ion peak 
Table 2. Detection limit of model peptides

\begin{tabular}{|c|c|c|c|c|c|c|}
\hline \multirow[t]{3}{*}{ Peptide } & \multirow{2}{*}{\multicolumn{2}{|c|}{$\begin{array}{c}{[\mathrm{M}+\mathrm{H}]^{+}} \\
\text {Detection limit }\end{array}$}} & \multirow{3}{*}{$\mathrm{S} / \mathrm{N}$} & \multicolumn{2}{|c|}{$[\mathrm{M}-\mathrm{H}]^{-}$} & \multirow{3}{*}{$\mathrm{S} / \mathrm{N}$} \\
\hline & & & & & limit & \\
\hline & Amount deposited & Analyte concentration & & Amount deposited & Analyte concentration & \\
\hline $\mathrm{T} 7$ & $1 \mathrm{pmol}$ & $360 \mathrm{nmol} / \mathrm{m}^{2}$ & 5.8 & $1 \mathrm{pmol}$ & $360 \mathrm{nmol} / \mathrm{m}^{2}$ & 2.4 \\
\hline RT6 & $10 \mathrm{fmol}$ & $3.6 \mathrm{nmol} / \mathrm{m}^{2}$ & 4.3 & $10 \mathrm{pmol}$ & $3.6 \mu \mathrm{mol} / \mathrm{m}^{2}$ & 52.8 \\
\hline T6R & $10 \mathrm{fmol}$ & $3.6 \mathrm{nmol} / \mathrm{m}^{2}$ & 3.1 & $10 \mathrm{pmol}$ & $3.6 \mu \mathrm{mol} / \mathrm{m}^{2}$ & 15.3 \\
\hline RT5F & $10 \mathrm{fmol}$ & $3.6 \mathrm{nmol} / \mathrm{m}^{2}$ & 5.5 & $1 \mathrm{pmol}$ & $360 \mathrm{nmol} / \mathrm{m}^{2}$ & 3.1 \\
\hline FT5R & $10 \mathrm{fmol}$ & $3.6 \mathrm{nmol} / \mathrm{m}^{2}$ & 4.8 & $1 \mathrm{pmol}$ & $360 \mathrm{nmol} / \mathrm{m}^{2}$ & 2.3 \\
\hline KT6 & $100 \mathrm{fmol}$ & $36 \mathrm{nmol} / \mathrm{m}^{2}$ & 4.5 & $10 \mathrm{pmol}$ & $3.6 \mu \mathrm{mol} / \mathrm{m}^{2}$ & 6.9 \\
\hline A1 & $1 \mathrm{fmol}$ & $360 \mathrm{pmol} / \mathrm{m}^{2}$ & 3.8 & $10 \mathrm{fmol}$ & $3.6 \mathrm{nmol} / \mathrm{m}^{2}$ & 4.3 \\
\hline A1p1 & $1 \mathrm{fmol}$ & $360 \mathrm{pmol} / \mathrm{m}^{2}$ & 2.5 & $10 \mathrm{fmol}$ & $3.6 \mathrm{nmol} / \mathrm{m}^{2}$ & 3.8 \\
\hline A1p2 & $50 \mathrm{fmol}$ & $18 \mathrm{nmol} / \mathrm{m}^{2}$ & 2.9 & $100 \mathrm{fmol}$ & $36 \mathrm{nmol} / \mathrm{m}^{2}$ & 5.3 \\
\hline $\mathrm{A} 2$ & $10 \mathrm{fmol}$ & $3.6 \mathrm{nmol} / \mathrm{m}^{2}$ & 8.3 & $25 \mathrm{fmol}$ & $9 \mathrm{nmol} / \mathrm{m}^{2}$ & 5.9 \\
\hline A3 & $10 \mathrm{fmol}$ & $3.6 \mathrm{nmol} / \mathrm{m}^{2}$ & 5.6 & $100 \mathrm{fmol}$ & $36 \mathrm{nmol} / \mathrm{m}^{2}$ & 3.2 \\
\hline A4 & $10 \mathrm{fmol}$ & $3.6 \mathrm{nmol} / \mathrm{m}^{2}$ & 3.2 & $100 \mathrm{fmol}$ & $36 \mathrm{nmol} / \mathrm{m}^{2}$ & 3.2 \\
\hline A5 & $100 \mathrm{fmol}$ & $36 \mathrm{nmol} / \mathrm{m}^{2}$ & 1.9 & $10 \mathrm{fmol}$ & $3.6 \mathrm{nmol} / \mathrm{m}^{2}$ & 2.5 \\
\hline A6 & $1 \mathrm{fmol}$ & $360 \mathrm{pmol} / \mathrm{m}^{2}$ & 2.6 & $10 \mathrm{fmol}$ & $3.6 \mathrm{nmol} / \mathrm{m}^{2}$ & 2.5 \\
\hline
\end{tabular}

demonstrates that the detection limit of the ACTH series was lower than that of the T-clusters. For example, study of the arginine containing peptides A1, A6, and RT6 shows that the detection limits of $[\mathrm{M}+\mathrm{H}]^{+}$for $\mathrm{A} 1$ and $\mathrm{A} 6$ (about 1 fmol) are 10 times lower than for RT6. Although both T6R and A2 contain an Arg residue at the C-terminus, the A2 peptide of the ACTH series shows a lower detection limit than T6R. A similar trend was obtained from the comparisons of other peptides, such as the lysine containing peptides KT6 and A4, and the basic amino acid-free peptides $\mathrm{T} 7$ and A5. The increase in the ion yield of the ACTH-based peptides compared with the T-clusters may be due to the fact that the ACTH series have two or three aromatic amino acid residues. The positive effect of aromatic amino acid residues on the ion yields is interpreted via the term corresponding to the rate of desorption of analyte molecules, $J_{v}$ in Equation 1.

In the case of negative ion mode, the detection limit of $[\mathrm{M}-\mathrm{H}]^{-}$in the ACTH series was approximately 100 times lower than that of T-clusters. The characteristic constituent amino acids of the ACTH series compared with the Tclusters are aromatic amino acids such as Phe and Tyr residues and acidic amino acids such as Glu and Asp residues. It is expected that the presence of aromatic amino acid residues contributes to the increase in the ion yield of $[\mathrm{M}-\mathrm{H}]^{-}$by means of the rate of desorption of analyte molecules, $J_{v}$ in Equation 1. Additionally, three or four
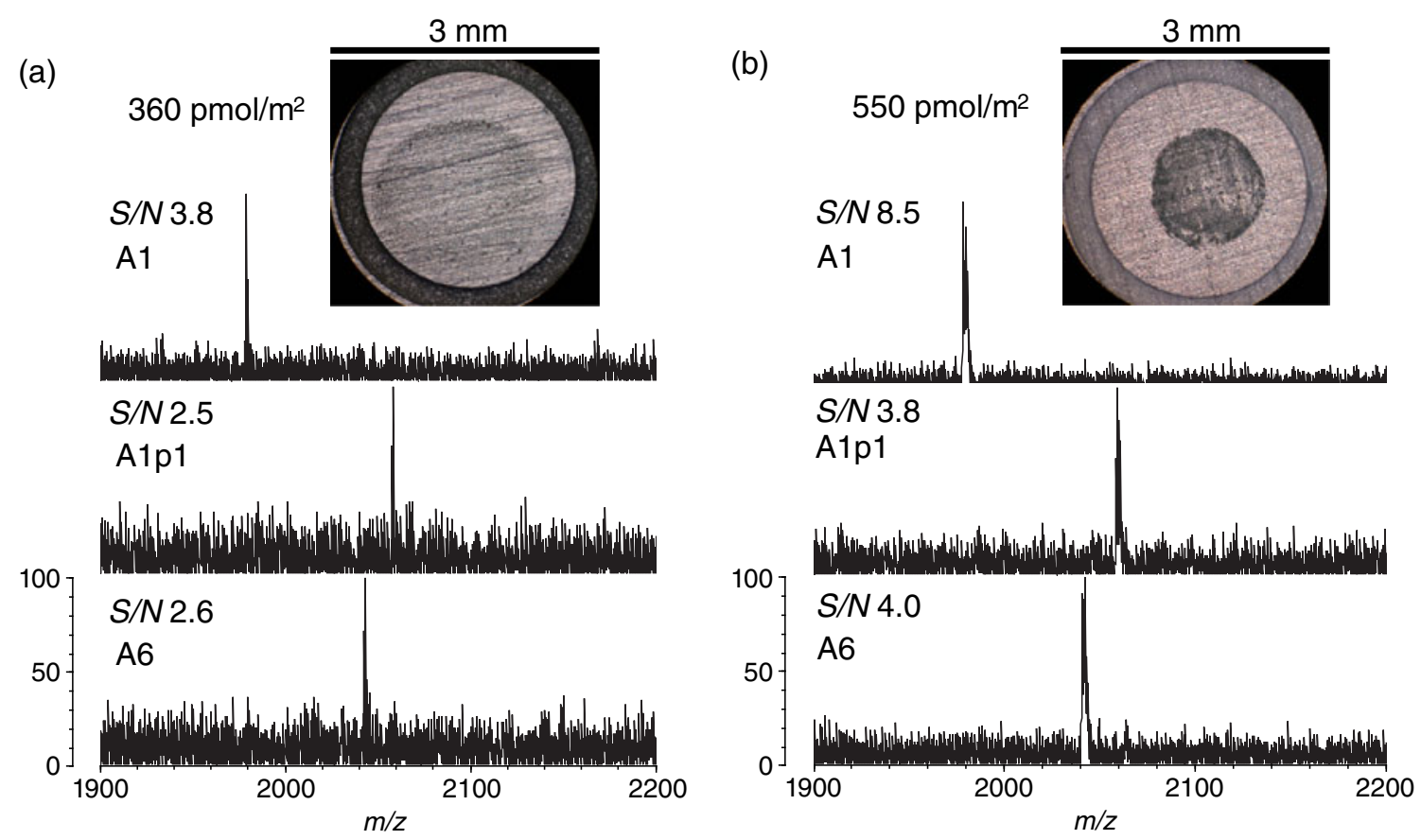

Figure 5. Positive ion MALDI mass spectra from $1 \mathrm{fmol} A 1$ (upper), $1 \mathrm{fmol} \mathrm{A1p1} \mathrm{(middle),} \mathrm{and} 1 \mathrm{fmol}$ of A6 (lower). (a) using stainless plate, and (b) using Teflon seat on the stainless plate 
acidic amino acid residues in the ACTH series contribute a positive influence on the ion yields of $[\mathrm{M}-\mathrm{H}]^{-}$.

\section{Influence of the Concentration with a Teflon Sheet on the Ion Yields}

To evaluate the influence of the concentration of peptides loaded on the surface of the stainless plate on the ion yields, a stainless plate and a Teflon covered stainless plate were used for a comparison of ion yields. The use of the Teflon covered plate results in a higher concentration of peptide solution on the surface, which would then be expected to have higher capability to desorb or vaporize from the matrix crystal surface. The amount of analyte deposited on the stainless plate was $1 \mathrm{fmol}$ with a spot size of $2.79 \pm 0.35 \times 10^{-6} \mathrm{~m}^{2}$. This corresponds to an equivalent analyte concentration of 360 $\mathrm{pmol} / \mathrm{m}^{2}$. In contrast, when using the Teflon covered stainless plate the sample spot size was $1.83 \pm 0.30 \times 10^{-6} \mathrm{~m}^{2}$, which is 1.5 times smaller than the size of the spot on the stainless plate alone. Optical images of the dried sample on the stainless plate and Teflon covered plate are shown in the insets of Figure $5 \mathrm{a}$ and $\mathrm{b}$, respectively. Figure 5 shows the positive-ion MALDI mass spectra of 1 fmol A1, A1p1, and A6 obtained with the stainless and Teflon covered stainless plate. The $\mathrm{S} / \mathrm{N}$ values for $\mathrm{A} 1, \mathrm{~A} 1 \mathrm{p} 1$, and $\mathrm{A} 6$ in Figure $5 \mathrm{~b}$ are 2.24, 1.52, and 1.54 times higher than those in Figure 5a. This indicates that the ion yields are dependent on the surface concentration of analyte, and such an influence is interpreted via the term corresponding to the rate of desorption of neutral molecules, $J_{v}$ in Equation 1.

\section{Conclusions}

In the work described here, the influence of Arg, Lys, and Phe residues and phosphorylation on the ion yields of model peptides and the detection limits for both ions of $[\mathrm{M}+\mathrm{H}]^{+}$ and $[\mathrm{M}-\mathrm{H}]^{-}$have been studied in positive- and negativeion MALDI-MS. The results obtained have been interpreted from the standpoint of two different components, namely, desorption and ionization, on the basis of physicochemical properties of constituent amino acids. The presence of basic amino acid residues such as Arg and Lys facilitates the protonation reaction and thus enhances the ion yield of $[\mathrm{M}+$ $\mathrm{H}]^{+}$. An N-terminal rather than a C-terminal Arg residue is advantageous for the formation of both $[\mathrm{M}+\mathrm{H}]^{+}$and $[\mathrm{M}-$ $\mathrm{H}]^{-}$. The presence of a Lys residue increases the formation of $[\mathrm{M}+\mathrm{H}]^{+}$, though the formation of $[\mathrm{M}-\mathrm{H}]^{-}$is suppressed. The results obtained indicate that positive- and negative-ion formation occurs simultaneously and competitively under MALDI conditions. The presence of aromatic amino acid residues such as Phe contributes to enhancement of the ion yields of both $[\mathrm{M}+\mathrm{H}]^{+}$and $[\mathrm{M}-\mathrm{H}]^{-}$. This indicates that the presence of aromatic amino acids in peptides is a positive factor for the production of both protonated and deprotonated peptides. The presence of phosphate group(s) contributes to suppression of the ion yields of both $[\mathrm{M}+\mathrm{H}]^{+}$and $[\mathrm{M}-\mathrm{H}]^{-}$due to the loss of phosphate group.

\section{Acknowledgments}

M.T. acknowledges support from the Creation of Innovation Centers for Advanced Interdisciplinary Research Area in the Special Coordination Fund for Promoting Science and Technology, and a Grant-in-Aid for Scientific Research (C) (20550081) from the Japan Ministry of Education, Culture, Sports, and Technology. D.A. acknowledges research fellowship from the Japan Society for the Promotion of Science for Young Scientists (23-10272).

\section{References}

1. Karas, M., Bachmann, D., Bahr, U., Hillenkamp, F.: Matrix-assisted ultraviolet laser desorption of non-volatile compounds. Int. J. Mass Spectrom. Ion Processes 78, 53-68 (1987)

2. Tanaka, K., Waki, H., Ido, Y., Akita, S., Yoshida, Y., Yoshida, T.: protein and polymer analysis up to $m / z 10,000$ by laser ionization-TOFMS. Rapid Commun. Mass Spectrom. 2, 151-153 (1988)

3. Karas, M., Hillenkamp, F.: Laser desorption ionization of protein with molecular masses exceeding 10,000 Daltons. Anal. Chem. 60, 22992301 (1988)

4. Whitehouse, C.M., Dreyer, R.N., Yamashita, M., Fenn, J.B.: Electrospray interface for liquid chromatographs and mass spectrometers. Anal. Chem. 57, 675-679 (1985)

5. Fenn, J.B., Mann, M., Meng, S.F., Wong, C.M.: Electrospray ionization for mass spectrometry of large biomolecules. Science 246, 60-71 (1989)

6. Henzel, W.J., Billeci, T.M., Stults, J.T., Wong, S.C., Grimley, C., Watanabe, C.: Identifying proteins from two-dimensional gels by molecular mass searching of peptide fragments in protein sequence databases. Proc. Natl. Acad. Sci. U.S.A. 90, 5011-5015 (1993)

7. Pappin, D.J.C., Hojrupt, P., Bleasbyl, A.J.: Rapid identification of proteins by peptide-mass fingerprinting. Curr. Biol. 3, 327-332 (1993)

8. Quist, A.P., Huth-Fehre, T., Sundqvist, B.U.R.: Total yield measurements in matrix-assisted laser desorption using a quartz crystal microbalance. Rapid Commun. Mass Spectrom. 8, 149-154 (1994)

9. Cotter, R.J.: Laser desorption chemical ionization mass spectrometry. Anal. Chem. 52, 1967-1970 (1980)

10. Speir, J.P., Gorman, G.S., Cornett, D.S., Amster, I.J.: Controlling the dissociation of peptide ions using laser desorption/chemical ionization Fourier transform mass spectrometry. Anal. Chem. 63, 65-69 (1991)

11. Coon, J.J., McHale, K.J., Harrison, W.W.: Atmospheric pressure laser desorption/chemical ionization mass spectrometry: a new ionization method based on existing themes. Rapid Commun. Mass Spectrom. 16, 681-685 (2002)

12. Van Breemen, R.B., Snow, M., Cotter, R.J.: Time-resolved laser desorption mass spectrometry. I. desorption of preformed ions. Int. J. Mass Spectrom. Ion Physics 49, 35-50 (1983)

13. Tembreull, R., Lubman, D.M.: Pulsed laser desorption with resonant two-photon ionization detection in supersonic beam mass spectrometry. Anal. Chem. 58, 1299-1303 (1986)

14. Leisner, A., Rohlfing, A., Berkenkamp, S., Hillenkamp, F., Dreisewerd, $\mathrm{K}$.: Infrared laser post-ionization of large biomolecules from an IRMALD(I) plume. J. Am. Soc. Mass Spectrom. 15, 934-941 (2004)

15. Huang, F., Fan, X., Murray, K.K.: Matrix-assisted laser desorption ionization of infrared laser ablated particles. Int. J. Mass Spectrom. 274, 21-24 (2008)

16. Shiea, J., Huang, M.-Z., Hsu, H.-J., Lee, C.-Y., Yuan, C.-H., Beech, I., Sunner, J.: Electrospray-assisted laser desorption/ionization mass spectrometry for direct ambient analysis of solids. Rapid Commun. Mass Spectrom. 19, 3701-3704 (2005)

17. Nishikaze, T., Takayama, M.: Study of factors governing negative molecular ion yield of amino acid and peptide in FAB, MALDI and ESI mass spectrometry. Int. J. Mass Spectrom. 268, 47-59 (2007)

18. Nishikaze, T., Takayama, M.: Cooperative effect of factors governing molecular ion yields in desorption/ionization mass spectrometry. Rapid Commun. Mass Spectrom. 20, 376-382 (2006) 
19. Kebarle, P., Verkerk, U.H.: Electrospray: from ions in solution to ions in the gas phase, what we know now. Mass Spectrom. Rev. 28, 898-917 (2009)

20. Cech, N.B., Enke, C.G.: Practical implications of some recent studies in electrospray ionization fundamentals. Mass Spectrom. Rev. 20, 362-387 (2001)

21. Valero, M.L., Giralt, E., Andreu, D.: An investigation of residuespecific contributions to peptide desorption in MALDI-TOF mass spectrometry. Lett. Peptide Sci. 6, 109-115 (1999)

22. Baumgart, S., Lindner, Y., Kuhne, R., Oberemm, A., Wenschuh, H., Krause, E.: The contributions of specific amino acid side chains to signal intensities of peptides in matrix-assisted laser desorption/ionization mass spectrometry. Rapid Commun. Mass Spectrom. 18, 863-868 (2004)

23. Janek, K., Wenschuh, H., Bienert, M., Krause, E.: Phosphopeptide analysis by positive and negative ion matrix-assisted laser desorption/ ionization mass spectrometry. Rapid Commun. Mass Spectrom. 15, 1593-1599 (2001)

24. Skurski, P., Rak, J., Simons, J., Gutowski, M.: Quasidegeneracy of zwitterionic and canonical tautomers of arginine solvated by an excess electron. J. Am. Chem. Soc. 123, 11073-11074 (2001)

25. Boersema, P.J., Mohammed, S., Heck, A.J.R.: Phosphopeptide fragmentation and analysis by mass spectrometry. J. Mass Spectrom. 44, 861-878 (2009)

26. Annan, R.S., Carr, S.A.: Phosphopeptide analysis by matrix-assisted laser desorption time-of-flight mass spectrometer. Anal. Chem. 68, 3413-3421 (1996)

27. Mann, M., Jensen, O.N.: Proteomic analysis of post-translational modifications. Nature Biotechnol. 21, 256-261 (2003) 